\title{
El camino de la liberalización del comercio en APEC: el plan de acción individual de México, 1996-2000
}

DOI: $10.32870 /$ mycp.v4i14.149

Dagoberto Amparo Tello*

$\lceil\mathrm{n}$ ntroducción

Pacífico (APEC) a iniciativa del entonces primer ministro de Australia, Robert Hawke. Entre los principales objetivos del foro destacan los siguientes: a) coordinar y conducir las fuerzas regionales para el mantenimiento y fortalecimiento de la estructura global de comercio multilateral; b) contribuir al crecimiento y desarrollo de la región y del mundo, y c) fomentar el flujo de bienes, servicios, capital y tecnología a través de la reducción de las barreras al comercio y la cooperación tecnológica. ${ }^{1}$

Después de una etapa de formación de consensos y de un sentido de comunidad en la región, de 1989 a 1993, APEC entró a otra etapa en la que los ideales y las propuestas para la operación del foro tenían que tratar de ponerse en práctica. Así, la Declaración de Bogor de los líderes de APEC, durante la reunión de 1994, significó un paso muy importante en la evolución de la cooperación económica en la región de AsiaPacífico y marcó el inicio del camino de la liberalización en APEC. El acuerdo para desmantelar todos los obstáculos impuestos al comercio y la inversión entre las economías de APEC en un lapso de 25 años, dio a la región mayor confianza. La Declaración aseguró que la tendencia a la apertura, la cual ha sido crucial para la creciente prosperidad e interdependencia de la región, y la desrregulación, serían sostenidas.

Las metas de Bogor, que reconocen las diferencias entre los países del foro desarrollados y en desarrollo, estipulan que los primeros deberán alcanzarlas en el año 2010 y los

* Investigador del Departamento de Estudios del Pacífico de la Universidad de Guadalajara.

ORCID http://orcid.org/0000-0003-0344-6895 segundos en el 2020. El reto para las economías de APEC, entonces, estriba en la reducción y, cuando sea posible, la eliminación de todos los impedimentos a las transacciones económicas internacionales entre los miembros de la región. Estos impedimentos pueden dividirse en varias categorías, principalmente: a) barreras tradicionales de acceso a los mercados (aranceles y/o medidas no arancelarias); b) incertidumbres, que incluyen recurrir a amenazas comerciales unilaterales; c) falta de infraestructura, y d) divergencia en estándares y procedimientos.

En este trabajo se pretende abordar, de modo sucinto, el análisis de la evolución de la primera categoría para el caso de México, cuya meta de liberalización es el año 2020. Es decir, ¿qué avances se han registrado en la eliminación de las barreras arancelarias y no arancelarias al comercio entre las economías del APEC y México? Cabe mencionar que éste es un avance, relativamente pequeño, de la idea de evaluar con una mayor profundidad y rigor los Planes de Acción Individual (PAI) de todas y cada una de las economías miembro. Para esto, dada la complejidad y dificultad de la empresa, sería necesaria la conjunción de esfuerzos y recursos, humanos y materiales, para elaborar un proyecto viable con miras a realizar tal estudio.

\section{APEC y los Planes de Acción Individuales}

En la reunión de 1995, en Osaka, Japón, se estableció, en la Agenda de Acción de Osaka, que cada una de las economías miembro presentaría, en la siguiente reunión de 1996, en Filipinas, un programa de reformas propuestas, que luego se denominó Planes de Acción Individuales, para los años siguientes a fin de aumentar la confianza en que las metas de 2010 y 2020 serían logradas. El Plan de Acción de Manila para APEC inaugura la presentación de los PAI de las entonces 18 economías miembro. 
A partir de ese año se han presentado anualmente dichos PAI, donde se reportan los avances logrados en el año en cuestión y los que se proponen, o a los que se comprometen de manera voluntaria para el siguiente.

En un trabajo publicado en 1997 por uno de los estudiosos de APEC, Peter A. Petri, establecía que "la mayoría de los Planes de Acción Individuales (PAIs) son vagos en las metas generales y se quedan cortos [al definir] las específicas. La implementación, por supuesto, está sólo en sus etapas muy tempranas". ${ }^{2} \mathrm{De}$ aquí se desprende que, a pesar de las pautas definidas en Osaka, APEC carece de un marco concreto para establecer las metas o medir los avances.

\section{Los Planes de Acción Individual de México (1996-2000)}

Ahora bien, lo que se encontró en esta primera aproximación al PAI de México, en la parte que corresponde a los aranceles y medidas no arancelarias, después de cinco documentos presentados, es que las condiciones iniciales mencionadas anteriormente, en términos generales, no se cumplen. Esto quizá se deba a que esta parte es una de las que se prestan a una evaluación y medición en condiciones relativamente más concretas.

En el PAI de 1996 se menciona que México inició, en 1983, un proceso de liberalización unilateral y reducción de aranceles sobre la base de Nación Más Favorecida (NMF). Esta reducción fue muy fuerte, pues si se toma como base 1982, cuando el arancel máximo era de 100 por ciento, el arancel promedio de 27 por ciento, el arancel promedio ponderado de 16.4 por ciento y la dispersión arancelaria de 24.8 por ciento, en 1996 tales valores se ubicaron en 35 por ciento el arancel máximo, el arancel promedio en 12.6 por ciento, el arancel promedio ponderado en 9.9 por ciento y la dispersión arancelaria en 7.6 por ciento (véase Cuadro $1)$.

En la parte de barreras no arancelarias, en 1982 todas las importaciones requerían permisos previos. Pero a partir de 1983 se empezaron a eliminar $\mathrm{y}$, como parte de los compromisos adquiridos por México con su entrada al GATT, una gran proporción de dichos permisos se sustituyeron por aranceles, de manera que las importaciones sujetas a barreras no arancelarias se redujeron a sólo 10 por ciento en 1991. Así, en 1996, sólo 1.3 por ciento de las fracciones arancelarias requerían permisos de importación. Los sectores en que aplican restricciones o prohibiciones a la importación o exportación son: a) petróleo, en el que se reserva el derecho a permisos para importar o exportar a PEMEX; b) vestido y textiles, donde se requieren permisos para importar sólo ropa usada; c) químicos y artículos fotográficos, donde se necesitan permisos de importación sólo para ciertos farmoquímicos; d) equipo de transporte, que requiere permiso para importar automóviles y camiones, y e) maquinaria no eléctrica, donde sólo algunas están sujetas a permisos de importación. ${ }^{3}$

Con esta base, México se comprometió, a corto plazo, a participar en las negociaciones de un posible Acuerdo sobre Tecnología de la Información, en el marco de la OMC, que incluía la eliminación de aranceles en cinco etapas anuales iguales, iniciando el 1ero. de enero de 1999 , en varias fracciones arancelarias, tales como partes de computadora, máquinas de proceso automatizado de datos, unidades de proceso digital, etc., además de continuar con la 
Cuadro 1

Evolución arancelaria de México, 1982-1999

(Porcentajes)

\begin{tabular}{lrrrrr}
\hline Aranceles & 1982 & 1996 & 1997 & 1998 & 1999 \\
Promedio & 27 & 12.5 & 13.3 & 13.3 & N.D. \\
Promedio Ponderadp & 16.4 & 9.9 & 2.7 & 2.6 & 2.9 \\
Dispersión & 24.8 & 7.6 & 7.9 & 7.4 & $7.8^{*}$ \\
Máximo & 100 & 35 & 35 & 35 & 35 \\
\hline
\end{tabular}

N.D.: no disponible

* Corresponde a los primeros cinco meses del año.

Fuente: Elaboración propia con base en los Planes de Acción Individual de México, 1996-1999.

revisión de más reducciones arancelarias de manera unilateral, de acuerdo con su sector privado, y acelerar los acuerdos para la reducción de aranceles en el marco de la OMC, si los miembros y no miembros de APEC así lo acordaran.

En el mediano y largo plazo los compromisos fueron: a) examinar reducciones arancelarias progresivas; b) promover un mayor entendimiento de los beneficios de dichas reducciones arancelarias en la región de AsiaPacífico con el sector privado, para fomentar su apoyo y participación, y c) lograr el comercio libre y abierto en el 2020 por medio del desarrollo de enfoques recíprocos multilaterales o regionales.

Los compromisos en materia de barreras no arancelarias en el corto plazo fueron: a) revisar las medidas no arancelarias existentes con la intención de disminuirlas y facilitar el comercio en la región de Asia-Pacífico, y b) identificar las medidas no arancelarias con un nivel arancelario a fin de asegurar mayor transparencia. Al mismo tiempo, proveer información sobre las medidas no arancelarias para incorporarlas a la base de datos computarizados sobre aranceles. Mientras que en el mediano y largo plazo los compromisos fueron: a) desarrollar y publicar procedimientos claros y transparentes para la aplicación de las barreras no arancelarias, y b) disminuir, donde fuera apropiado, algunas otras medidas no arancelarias.

El PAI de 1997, por su parte, es muy similar al del año anterior y sólo tiene cambios pequeños que confirman ya las medidas a adoptar con base en el Acuerdo sobre Tecnologías de la Información, y el apoyo al inicio de una nueva ronda comprehensiva de negociaciones multilaterales hacia el fin del milenio. ${ }^{4}$

El PAI de 1998, por otro lado, contiene algunos avances sustanciales. En éste se consignan ya ciertas medidas adoptadas con base en los compromisos adquiridos en los años anteriores. Así, se reporta que, de acuerdo con el espíritu de APEC, México eliminó unilateralmente los aranceles sobre lana y carbón, con el interés de facilitar y aumentar el comercio de esos productos entre las economías del foro, y que está revisando mayores reducciones arancelarias, especialmente en el caso de insumos y maquinaria producida en las economías de APEC. Este último, además, lo asume como compromiso a corto plazo, en tanto que los de largo plazo se mantienen prácticamente iguales a los de los dos años anteriores. ${ }^{5}$

En la parte correspondiente a las barreras no arancelarias encontramos que se informa de la publicación de un volumen en el que se citan todos los permisos de importación sujetos a aprobación por parte de la Secretaría de Comercio y Fomento Industrial (SECOFI), lo que había sido uno de los compromisos adquiridos por México en 1997.

En el PAI de 1999 México reporta que se publicaron en el Diario Oficial las modificaciones de los regímenes arancelarios de las maquiladoras y las PITEX, mismas que entraron en efecto en noviembre de 2000. Esta medida da a los inversionistas mayor seguridad con 
respecto a la operación de los programas mexicanos de exportación, y beneficia a los inversionistas de las economías de APEC en México. Además, nuestro país publicó reducciones arancelarias unilaterales para insumos y maquinaria producida en las economías miembro del foro. Así, los fabricantes de productos eléctricos y electrónicos en México serán capaces de importar sus insumos y maquinaria a tasas reducidas o iguales a cero, con el compromiso de poner en práctica mayores reducciones arancelarias en estos rubros particulares. ${ }^{6}$

En la parte correspondiente a las barreras no arancelarias, se reporta que, en cumplimiento a los acuerdos adoptados en la OMC y del artículo XXIX del GATT, México sigue eliminando barreras no arancelarias, sustituyendo licencias de importación por aranceles. Así, en marzo de 1998, México publicó un Acuerdo que elimina las licencias de importación requeridas para 12 productos farmacéuticos a partir de enero de 1999, lo que a la fecha de presentación del PAI ya había tenido lugar. Esta mecánica se convierte, además, en un compromiso para futuras sustituciones de este tipo.

Por último, en el PAI del año 2000 lo más relevante es que se consigna la puesta en práctica de medidas para reducir de manera significativa los aranceles sobre importaciones de bienes de capital e intermedios desde economías de APEC con las que no haya acuerdo de libre comercio. Se argumenta que esas medidas beneficiarán las exportaciones hacia México de bienes de capital e intermedios desde tales economías, en particular en industrias tales como productos eléctricos y electrónicos, juguetes, ropa deportiva, fotografía, maquinaria agrícola, equipo médico y medicamentos, etc. Esas medidas se espera que beneficien a cerca del 90 por ciento de tales exportaciones hacia México, la mayoría de las cuales serán introducidas al país sin pagar derechos o con un pago no superior al 5 por ciento. ${ }^{7}$

Por lo que toca a las barreras no arancelarias, este apartado se mantiene prácticamente igual que el presentado el año anterior.

\section{Conclusiones}

Después de esta aproximación a los PAI de México presentados hasta la fecha, se notan ciertos avances que, si bien no son espectaculares, muestran una evolución paulatina hacia las metas de Bogor, por lo menos en lo que toca a la categoría de las barreras tradicionales al comercio, arancelarias y no arancelarias. De este modo, a poco más de cinco años de iniciado el proceso de liberalización comercial en APEC, es decir, una vez que se ha recorrido una quinta parte del camino, es notorio cierto grado de avance. Lo anterior tiene un valor mayor si consideramos que las medidas adoptadas en su mayoría han sido de manera unilateral y voluntaria. Esto seguramente dará la confianza necesaria y marcará la pauta para emprender acciones más fuertes y contundentes que permitan el logro de las metas establecidas en Bogor.

Además, se puede concluir que es posible iniciar una evaluación integral y profunda de los PAIs para todas las economías miembro, de modo que se pueda medir el progreso hacia las metas de Bogor de cada una de las economías del foro y establecer comparaciones, donde sea factible, entre los avances mostrados por cada una de ellas. Sin duda, esto significaría una contribución importante para las etapas posteriores del camino de APEC hacia la consecución de sus principales objetivos.

\section{Notas}

1 El subrayado es mío.

2 "Measuring and Comparing Progress in APEC", ASEANEconomic Bulletin, Vol. 4, núm. 1, julio de 1997, p. 1.

3 Mexico's Individual Action Plan 1996, en www.apecsec.org.sg/virtualib/history/mapa/vol2/ iapmex.exe.

4 Mexico's Individual Action Plan 1997, en www. apecsec.org.sg/download/iap97/iap97mex.exe.

5 Mexico's Individual Action Plan 1998, en www. a pecsec.org.sg/download/iap98/Mexico/ 98mexico_iap.exe.

6 Mexico's Individual Action Plan 1999, en www. apecsec.org.sg/download/iap99/mex_iap.exe.

7 Mexico's Individual Action Plan 2000, en www. apecsec.org.sg/iap/2000/mx2000ap.exe. 